\title{
COMPARISON OF MULTI LAYER PERCEPTRON (MLP) AND RADIAL BASIS FUNCTION (RBF) FOR CONSTRUCTION COST ESTIMATION: THE CASE OF TURKEY
}

\author{
Savas BAYRAM ${ }^{\mathrm{a}}$, M. Emin OCAL ${ }^{\mathrm{b}}$, Emel LAPTALI ORAL ${ }^{\mathrm{b}}$, C. Duran ATIS ${ }^{\mathrm{a}}$ \\ a Department of Civil Engineering, Erciyes University, 38039, Melikgazi, Kayseri, Turkey \\ ${ }^{b}$ Department of Civil Engineering, Cukurova University, 01330, Balcali, Adana, Turkey
}

Received 13 Mar 2013; accepted 29 May 2013

\begin{abstract}
In Turkey, for the preliminary construction cost estimation, a notice, which is updated and published annually by Turkish Ministry of the Environment and Urbanism, known as "unit area cost method" (UACM) is generally employed. However, it's known that the costs obtained through this method in which only construction area is taken into consideration have significant differences from actual costs. The aim of this study is to compare the cost estimations obtained through "multi layer perceptron" (MLP) and "radial basis function" (RBF), which are commonly used artificial neural network (ANN) methods. The results of MLP and RBF were also compared with the results of UACM and the validity of UACM was interpreted. Dataobtained from 232 public construction projects, which completed between 2003 and 2011 in different regions of Turkey, were reviewed. Consequently, estimated costs obtained from RBF were found to be higher than the actual costs with a $0.28 \%$ variance, while the estimated costs obtained from MLP were higher than actual values with a $1.11 \%$ variance. The approximate costs obtained from UACM are higher than actual costs with a $28.73 \%$ variance. It was found that both ANN methods were showed better performance than the UACM but RBF was superior to MLP.
\end{abstract}

Keywords: actual cost, construction cost estimation, unit area cost method (UACM), artificial neural networks (ANN), multi layer perceptron (MLP), radial basis function (RBF).

\section{Introduction}

At the present time, construction process has been modified with the affect of technological developments on construction sector and more qualified buildings are constructed (Uğur 2007a). However, the obligation to exploit resources in a rational way enhances the significance of studies performed for cost estimation either at the design phase and the construction phase (Uğur 2007b; Ashworth 2010). In Turkey, for the cost estimation during predesign stage, "the Notice Concerning the Approximate Construction Unit Costs to Be Used While Calculating the Service Charge of Architecture and Engineering", which is updated and published annually by Turkish Ministry of Environment and Urbanism, known as "unit area cost method" (UACM) is generally employed. In this method, approximate cost is obtained by multiplying the total construction area of a building and the construction cost of the unit area for the building according to the construction class of the notice. However, UACM is commonly used because of the practical application and it's known that the cost values obtained by using this method in which only construction area is taken into consideration have significant differences from actual construction cost values. Realistic estimation of construction cost is a vital issue for the parties of construction like employer, contractor and project manager. Therefore, development of a method, which estimates the construction costs realistically, is still a problem to be investigated. In recent years, the number of studies on the use of artificial intelligence methods in the cost estimation of constructions increases rapidly (Adeli, Wu 1998; Liu 1998; Bhokha, Ogunlana 1999; Siqueira 1999; Emsley et al. 2002; Kim et al. 2004, 2005; Günaydın, Doğan 2004; Sönmez 2004; Uğur 2007a; Helvaci 2008; Bari et al. 2008; Kuşan et al. 2009; Arafa, Alqedra 2011; Baalousha, Çelik 2011; Bayram et al. 2012). The most important specific literatures regarding the issue are presented in the following;

Bhokha and Ogunlana (1999) studied on the application of ANN to forecast the construction duration of buildings at the pre-design stage. The data were obtained from 136 different building projects, which were built between 1987 and 1995 years in Bangkok, Thailand. Buildings over 23 meters and total construction area over $10000 \mathrm{~m}^{2}$ were taken into consideration. Input parameters of the ANN model were considered as; function of construction, bearing system, functional area, building

Corresponding author: Savas Bayram

E-mail:sbayram@erciyes.edu.tr 
height, complexity of foundation works, quality of siding/ decoration and site transportation, while the construction duration was considered as an output parameter. A threelayered back-propagation network consisting of 11 input nodes was constructed. 68 data were used for the training stage while the remaining 68 data were put aside to be used in the testing stage. The average error of testing data was calculated as $18.2 \%$, while the total average error was calculated as 13.6\% (Bhokha, Ogunlana 1999).

Siqueira (1999) developed a cost estimation method based on ANN and regression analysis (RA) in order to estimate the costs of low-rise prefabricated steel buildings. The data which were used in the study were obtained from 75 different building projects in Canada. The results of the proposed cost model were compared with the data obtained from the project. The results were showed that the proposed ANN model was superior to RA (Siqueira 1999).

Emsley et al. (2002) developed ANN based on cost models using collected data from 300 building projects. Data were collected from predominantly primary sources using real-life data contained in project files, with some data obtained from the building cost information service, supplemented with further information and some from a questionnaire distributed nationwide. Models based on linear regression techniques were used as a benchmark for evaluation of the ANN models. The best mean absolute percentage error (MAPE) was obtained as 16.6\% from ANN model (Emsley et al. 2002).

Kim et al. (2004) examined the performances of three different cost estimation models. These models were specified as multiple regression analysis (MRA), ANN and case-based reasoning (CBR). Cost data from 530 construction works were analyzed. Consequently, although ANN model was given more accurate estimation results, CBR was showed a better performance than the ANN when the long-term use was taken into consideration (Kim et al. 2004).

Günaydın and Doğan (2004) aimed to identify the benefits of an ANN model to overcome the cost estimation problems that appears in the early stages of the construction design process. For this purpose, cost and design data were obtained from 30 different projects. For the ANN model; total construction area, the ratio of the typical floor area to the total area of the building, the ratio of ground floor area to the total area of the building, number of floors, console direction of the building, foundation system of the building, floor type of the building and location of the core of the building were considered as input parameters while the cost of the structural system per square meter was considered as an output parameter. Unit costs of residential buildings in Turkey were estimated with ANN and the accuracy of cost estimation was by $93 \%$ (Günaydın, Doğan 2004).

Uğur (2007a) estimated the construction costs of multi-storey reinforced concrete buildings with similar qualifications by using unit cost method (UCM).
Additionally, ANN applications were also included to the study. The main evaluation criteria for ANN architecture were considered to be the height of the building, the number of the flats in a typical floor, typical floor area, heights of each floor, the total number of the floors, facade area, facade space area and mean flat area as calculated from the projects. Cost estimation was undertaken through regression analysis (RA) and the performance of the ANN was analyzed by comparing the results from these three methods. Consequently, it was emphasized that ANN model was superior to RA (Uğur 2007a).

Arafa and Alqedra (2011) aimed by developing an efficient model to estimate the cost of buildings at early stage using ANN. Databases of 71 building projects were collected from construction projects in Gaza Strip, Palestine. Data were analyzed through MLP method, which is one of the ANN approaches. The input parameters of the ANN model were comprised; ground floor area, typical floor area, number of storeys, number of columns, type of footing, number of elevators and number of rooms while the output layer was comprised early cost estimate. The results of the model were indicated that ANN reasonably succeeded in predicting the early stage cost estimation of buildings using basic information of projects without the need for a more detailed design (Arafa, Alqedra 2011).

Baalousha and Çelik (2011) developed an artificial neural network model for unit price analysis with inflation adjustment system called "DANUP" for forecasting the cost indices in Turkey for the project period. A web based system was developed to facilitate the collection of construction cost information and communication. Thus, accessing the database through the internet and performing certain transactions according to user authorization were provided. Consequently, it was emphasised that the accuracy and precision of the system was much higher than hand calculation (Baalousha, Çelik 2011).

Bayram et al. (2012) compared the actual costs of public buildings with unit area cost method (UACM) results. Construction cost data from 198 projects; completed between 2004 and 2010 from Izmir, the third largest city in Turkey, were used. It was emphasized that UACM was unable to estimate the construction costs realistically. Besides, the projected and actual schedule and cost values were obtained and based on these values, cost variations and schedule variations were calculated. Cost variations and schedule variations were analyzed by multi layer perceptron (MLP) and grid partitioning algorithm (GPA). RMSE value was calculated as 2.65 from MLP while as 27.04 from GPA for cost variation. For schedule variation, RMSE value was calculated as 9.01 from MLP while as 49.96 from GPA. As a result, it was found that the MLP approach was better than GPA approach about its ability on the estimation of cost variations and schedule variations for construction projects (Bayram et al. 2012).

The literature studies show that artificial intelligence methods have an area of utilization besides tra- 
ditional methods for construction cost estimation and satisfactory performances have been obtained from these methods. However, in order to universalize the results of this study, the actual construction project data were obtained from three geographic regions of Turkey. The files of 232 building projects in total were reviewed and actual costs were compared with the approximate costs calculated through UACM. As an addition, a cost model was developed and analyzed with MLP and RBF methods, the results of these ANN applications and the results of UACM were compared directly. It's considered that these features of present study have revealed several differences from previous studies.

\section{Method}

Methods which are used for construction cost estimation and control of every stage of the process can differ according to their intended use (Uğur 2007a; Akınbingöl, Gültekin 2005). Estimation concept, which appeared for the first time in the 1950's of Europe, has been classified as a result of research and development works after 1980's (Uğur 2007a; Akınbingöl, Gültekin 2005). Many different factors are considered for the classification of construction cost estimation methods. For instance, a classification is; traditional models, descriptive models, realistic models and advanced models (Uğur 2007a, 2009; Akınbingöl, Gültekin 2005). Construction cost estimation methods are divided into three groups in another classification such as; statistics-probability analysis, comparison with similar projects and artificial intelligence techniques (Göktürk 2007). In Turkey, while some of these methods are commonly used, some of them have just started to be used. Realistic determination of construction costs is troublesome due to; distinction of usage purposes (education, health, etc.), variability of project designs, and diverseness of project inputs (employer, contractor, materials, etc.) and the varying of initial demands during construction. Considering shortness of the scope of statistical data and price changes due to inflation rates fluctuations in Turkey, significant variances occur for the construction cost estimates (Kolaylığlu 2006; Göktürk 2007).

In this study, unit area cost method (UACM), which is updated and published annually by Turkish Ministry of Environment and Urbanism, was initially used to determine its ability for construction cost estimation. The other current method is artificial neural network (ANN), based on artificial intelligence methods. Artificial intelligence can be defined as; "comprehend the human's frame of mind and working on developing computer operations for simulation" (Uğur 2007a). Artificial intelligence techniques involve; several methods such as ANN, fuzzy logic (FL), genetic algorithm (GA) and mixed hybrid methods. In general terms, ANN may be defined as a system to model the method conducted by the brain to perform a task. Moreover, the ability of the ANN to obtain the concepts from previous data without requiring any mathematical formulation or algorithm is an advantage over other methods (Civelekoğlu 2006; Jain et al. 1996). Nowadays, for specific aims in various fields, numerous ANN methods (multi layer perceptron, radial basis function, Hopfield, self-organizing map, learning vector quantization, general regression neural network, etc.) have been developed (Kaynar et al. 2010). Multi layer perceptron (MLP) and radial basis function (RBF) are the general forms of ANN approach as a number of learning algorithms use these networks to instruct (Kim et al. 2005; Kaynar et al. 2010; Öztemel 2012). Therefore, comparative evaluation of the performances of MLP and RBF methods, which are widely used ANN approaches, is also aimed in this study.

MLP network usually consists of three layers; input, hidden and output (Oral et al. 2012). Input layer contains as many neurons as the number of parameters affecting the problem. One hidden layer is usually sufficient for nearly all problems. The number of the neurons in the hidden layer(s) should be selected arbitrarily (Oral et al. 2012). A neuron has a logistic activation function in the hidden layer(s) and linear activation function in the output layer (Kangilaski 2002; Oral et al. 2012). Thus, the hidden layer(s) squeezes the output to a narrow range, from which the output layer with linear function can predict all values (Werbos 1994; Fine 1999; Oral et al. 2012). Also for MLP method, training is achieved by using two steps. In the first step, a randomly selected input vector from the training data set is fed into the input layer. The output from the activated neurons is then propagated forward from hidden layer(s) to the output layer. The back propagation step, on the other hand, starts with calculating the error in the gradient descent and propagates it backwards to each neuron in the output layer, then the hidden layer. At the end of the second step, the weights and the biases of the neural network are recomputed. These two steps are alternately used until the network's overall error is less than a predefined rate, or until the number of maximum epochs is reached (Oral et al. 2012). Although MLP network is a widely used ANN approach, it has also some disadvantages like time consuming problem to reach a solution and trapping at local minima (Arslan et al. 2007).

RBF network, which was initially used for multivariate interpolation problems, was developed for ANN applications in time and it has been used as an alternative MLP network (Powel 1987; Broomhead, Lowe 1988; Chen et al. 1991; Bianchini et al. 1995). A RBF network similarly consists of three layers; input layer, one hidden layer and output layer (Kaynar et al. 2010). However, between the input layer and hidden layer, a non-linear transformation which contains radial basis activation functions is utilized (Öztemel 2012). A linear transformation is also utilized between the hidden layer and output layer. Besides, RBF network uses a mixed strategy which contains unsupervised learning and, as well as, supervised learning. Supervised learning is performed for the linear transformation, while unsupervised learning is performed for the non-linear transformation. It should be noted that 
RBF network uses a non-iterative technique (Hacioğlu 2006). In other words, RBF network is capable within the training data set. Therefore, RBF network is generally preferred for optimization studies (Hacioğlu 2006).

Besides the similarities like consisting of three layers, MLP network and RBF network have also several notable differences. For instance; MLP network has one or more hidden layer, while RBF network has only one hidden layer. Additively, computations of the hidden layer(s) neurons and output layer neurons are similar for MLP network while the computations of the hidden layer neurons and output layer neurons are quite a change for RBF network (Akbilgiç 2011). Neurons use logistic activation function in the hidden layer(s) for MLP network while they use radial basis activation function for RBF network. In other respects, MLP network uses iterative technique while RBF network uses non-iterative technique and also RBF analysis needs sooner training period than MLP analysis. The most important difference between MLP network and RBF network is seen as methods of generating solutions to problems (Akbilgiç 2011). Namely, MLP network presents general approach as a whole to handle nonlinear relationship between the input parameter(s) and output parameter(s) while RBF network evaluates the different subspaces of input set as different relationships and produces local solutions.

Within the scope of this study, the files of a total of 232 building projects were reviewed, which were procured in accordance with the Public Tender Law by Turkish Ministry of Environment and Urbanism and completed between 2003 and 2011 in Bursa, Ankara and Gaziantep, which are the metropolitans of Turkey's different geographic regions. A "cost model", which comprises five combinations of different input(s), was established for the ANN analyses and the input parameters of the cost model were comprised; approximate cost, total construction area, number of floors, building height and contract value while the output parameter was comprised actual cost. Analyses were repeated with MLP and RBF methods for the five combinations of cost model. Two standard error measures; root mean square error (RMSE) and mean absolute error (MAE), were calculated besides coefficient of determination $\left(\mathrm{R}^{2}\right)$, which is the square of coefficient of correlation, for the comparison of actual costs and estimated costs. Thus, the performances of ANN methods were comparatively evaluated.

\section{Application}

In the archive study carried out in Environment and Urbanism Provincial Directorates of Bursa, Ankara and Gaziantep, tender files of 24, 61 and 147 completed construction works and so totally 232 completed construction works were reviewed. All the works were consisted of public buildings and by the reason of the implementation in the same procedure, the obtained data from these three cities were collectively evaluated. The range of the actual cost values, which were obtained from archive study, can be seen with the currencies of Euros $(€)$ and Turkish Lira (TL) in Figure 1. For the monetary conversion, $€ 1$ was taken into account as average $2.30 \mathrm{TL}$.

Figure 1 indicates that $47.84 \%$ of the actual costs were less than 500,000 TL (€217,000). Also, minimum actual cost value was determined as $31000 \mathrm{TL}(€ 13480)$ and maximum actual cost value was determined as $3,039,059$ TL $(€ 1,321,330)$ while the average actual cost was calculated as $714,135.65$ TL $(€ 310,494)$.

For the UACM application, categorization of building classes based on the buildings' architecture services according to "the notice concerning the approximate construction unit costs to be used while calculating the service charge of architecture and engineering" was examined and the classification of every building was initially determined. Then, the notices published between 2003 and 2011 were examined and cost per square meter of every building was determined. Finally, the total construction area which was obtained from the archive studies was multiplied by the cost per square meter in accordance with the notice and the approximately calculated cost of every building. These cost values were compared with the actual costs and the validity of UACM approach, and it was interpreted in the "findings and discussion" part of this study.

ANN, which is one of the most significant artificial intelligence approaches, uses the examples (a total of 232 building projects) to identify the relations between the events and benefits from the learned relations as a tool to interpret the problems encountered in the future and to make a decision (Uncuoğlu 2003). Therefore, it's crucial to comprehend the problem and decide how the problem will be carried out to network structure. In this study, a
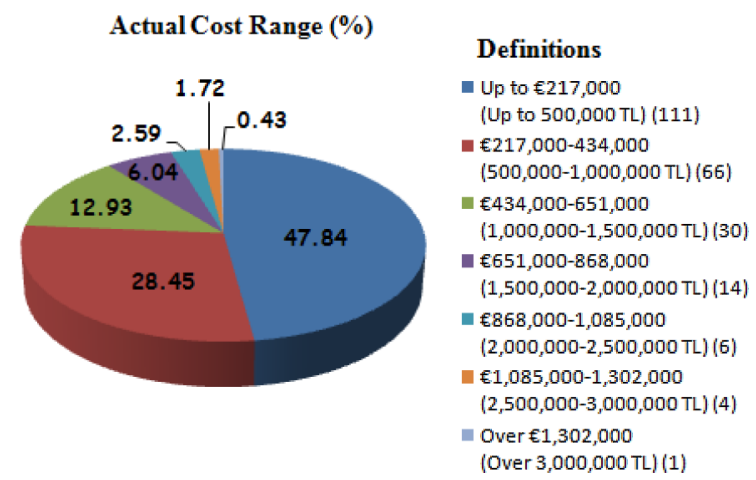

Fig. 1. Range of actual cost values (\%)

Table 1. Parameters of the cost model

\begin{tabular}{|c|c|c|c|c|c|}
\hline $\begin{array}{l}\text { Input } \\
\text { (1) }\end{array}$ & $\begin{array}{l}\text { Input } \\
\text { (2) }\end{array}$ & $\begin{array}{l}\text { Input } \\
\text { (3) }\end{array}$ & $\begin{array}{c}\text { Input } \\
\text { (4) }\end{array}$ & $\begin{array}{c}\text { Input } \\
\text { (5) }\end{array}$ & Output \\
\hline $\begin{array}{c}\text { Approximate } \\
\text { Cost } \\
\text { (TL) }\end{array}$ & $\begin{array}{c}\text { Total } \\
\text { Construction } \\
\text { Area }\left(\mathrm{m}^{2}\right)\end{array}$ & $\begin{array}{c}\text { Number } \\
\text { of } \\
\text { Floors }\end{array}$ & $\begin{array}{c}\text { Building } \\
\text { Height } \\
\text { (m) }\end{array}$ & $\begin{array}{c}\text { Contract } \\
\text { Value } \\
\text { (TL) }\end{array}$ & $\begin{array}{c}\text { Actual } \\
\text { Cost } \\
\text { (TL) }\end{array}$ \\
\hline
\end{tabular}


“cost model", which comprises five combinations, was proposed for the ANN analyses. The input parameters and the output parameter of the cost model can be viewed from Table 1. As a principle, every input parameter was included to model according to its turn. For instance; second input parameter was included to model in the second combination.

For the cost model; $72 \%$ (168 building projects) of the total data were used for the training stage while the remaining (64 data equal to $28 \%$ of the total data) were put aside to be used in the testing stage. Accordingly, the total of 85 data obtained from Bursa and Ankara with the 83 data obtained from Gaziantep between the years of 2003 and 2006 were used for the training stage, while the remaining 64 data obtained from Gaziantep between the years of 2006 and 2011 were used for the testing stage.

The combinations were trained through MLP and RBF methods and the learning performances of the networks were tested according to the prediction results. In order to compare the prediction results, two standard error measures; root mean square error (RMSE) and mean absolute error (MAE) were calculated for each data set by using Eqns (1) and (2). RMSE and MAE values for the training and testing data sets of both MLP and RBF methods are given in Table 4 . Besides, the coefficient of determination $\left(R^{2}\right)$ value was considered to be the determinant in arriving to the conclusions about the accuracy of both ANN models. $R^{2}$ values are presented the measure of dispersion, meaning that the smaller $R^{2}$ value, the more reliable model was in terms of stableness in predicting values (Oral et al. 2012). $R^{2}$ values were calculated for each data set by using Eqn (3) and also given in Table 4.

RMSE being close to zero shows the model's increasing ability to estimate (Eren, Eyüpoğlu 2011). RMSE is calculated through the Eqn (1), where; the $y_{\text {model }, i}$ and $y_{\text {real }, i}$ respectively show the model estimations and actual values and $n$ shows the number of data (Singh et al. 2009):

$$
R M S E=\sqrt{\frac{\sum_{i=1}^{n}\left(y_{\text {model } . i}-y_{\text {real }, i}\right)^{2}}{n}} .
$$

MAE is utilized to determinate the absolute error between actual values and model estimations. Similar to RMSE, MAE being close to zero shows the model's increasing ability to estimate. MAE is calculated through the Eqn (2) (Kaveh et al. 2008):

$$
M A E=\frac{1}{n} \sum_{i=1}^{n}\left|y_{\text {model }, i}-y_{\text {real }, i}\right|,
$$

$R^{2}$ is a statistical definition which reveals the numerical relationship between actual values and model estimations. $R^{2}$ can be referred as the square of the correlation coefficient and takes a value between 0 and 1. For instance, $R^{2}=1$ means that the dependence between the actual values and the model estimations are quite strong. $R^{2}$ expres- sion can be calculated through the Eqn (3) (Kumanlıoğlu, Fistıkoğlu 2011):

$$
R^{2}=1-\frac{\sum_{i=1}^{n}\left(y_{\text {model }, i}-y_{\text {real }, i}\right)^{2}}{\sum_{i=1}^{n} y_{\text {real }, i}^{2}}, 0 \leq R^{2} \leq 1 .
$$

MATLAB simulation software was employed for threelayered modeling requirements (MATLAB, Version 7.9.0, The Mathworks Inc). For the MLP analysis, minimum RMSE and MAE values were sought to be obtained by changing the number of neurons in the hidden layer and the number of iterations for each combination. The analysis was begun with the lowest number of hidden layers and iterations. Initially, the changes of RMSE, MAE and $R^{2}$ were observed while the iteration number was increased by 1-20 ranges. Then, the number of the hidden layers was changed by 1-10 ranges and the effect of the changes on RMSE, MAE and $R^{2}$ was observed. For all combinations, Levenberg-Marquard (trainlm) back propagation algorithm was employed as the training algorithm. Repeated analyses were performed with the use of logarithmic sigmoid (logsig) and tangent sigmoid (tansig) as activation functions between the hidden layer and output layer. Thus, the best-performing activation function was aimed to be determined. For the RBF analysis, the number of the hidden layers was changed by $1-10$ ranges while the spreading parameter value was changed by $0.1-2.0$ ranges and the effect of the changes on RMSE, MAE and $R^{2}$ was observed. Modeling performances of MLP and RBF methods were interpreted in the "findings and discussion" part of this study.

\section{Findings and discussion}

The correlation between the actual costs and approximate costs of 232 public buildings obtained through UACM can be seen in Figure 2.

Figure 2 indicates that; $y=x$ was a symmetric straight and the trend line was slided to $y$ axis with linear $y=1.187 x$ equation. It can be referred that data were scattered around the trend line. Hence, it's clear that actual cost data and approximate cost data, which were obtained through UACM, had significant differences. The correlation between actual cost data and approximate cost data validates this claim. It's known that if $R^{2}>0.80$, then there is a strong correlation between actual values and model estimations (Kayadelen et al. 2009). Thus, the result of $R^{2}=0.6954<0.80$ was at unacceptable level (Kayadelen et al. 2009).

On behalf of making interpretation on the scatter diagram given in Figure 2 numerically more tangible, distribution of the sum of actual costs and the sum of approximate costs, which were obtained through UACM, by years are given in Table 2 .

As can be seen from Table 2, total approximate costs obtained through UACM were found to be higher than the total actual costs with a $28.73 \%$ variance. When 


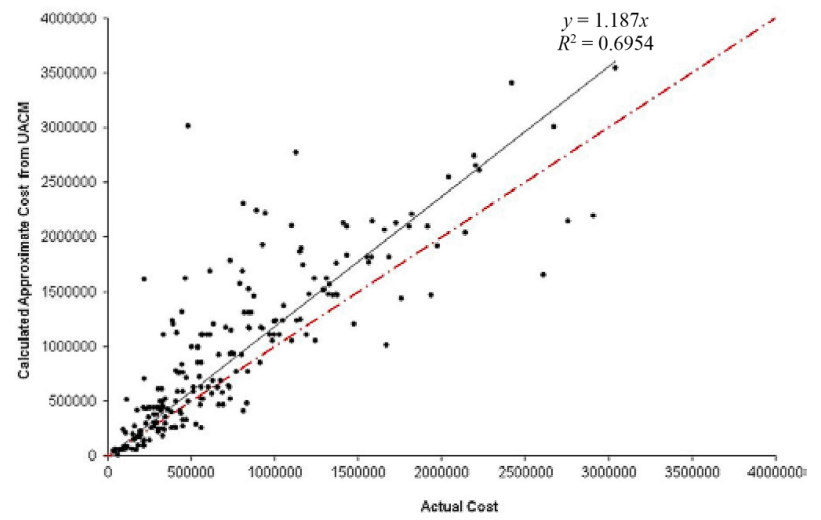

Fig. 2. Correlation between actual costs and UACM results

Table 2. Distribution of actual costs and UACM results (First line: $€$ values, Second line: (TL) values)

\begin{tabular}{|c|c|c|c|c|}
\hline Year & $\begin{array}{c}\text { Nr. } \\
\text { of Data }\end{array}$ & $\begin{array}{l}\text { UACM Results } \\
\qquad(a)\end{array}$ & $\begin{array}{l}\text { Actual Costs } \\
\text { (b) }\end{array}$ & $\begin{array}{c}(a-b) / b \\
(\%)\end{array}$ \\
\hline 2003 & 19 & $\begin{array}{c}\mathbf{6 , 7 1 2 , 7 8 6} \\
(15,439,408)\end{array}$ & $\begin{array}{c}\mathbf{3 , 6 3 5 , 5 5 7} \\
(8,361,780)\end{array}$ & 84.64 \\
\hline 2004 & 55 & $\begin{array}{c}\mathbf{1 5 , 1 6 2 , 3 3 0} \\
(34,873,358)\end{array}$ & $\begin{array}{c}\mathbf{8 , 8 3 3 , 6 4 6} \\
(20,317,386)\end{array}$ & 71.64 \\
\hline 2005 & 50 & $\begin{array}{c}\mathbf{2 3 , 2 8 9 , 6 3 7} \\
(53,566,165)\end{array}$ & $\begin{array}{c}\mathbf{1 8 , 4 9 2 , 2 8 9} \\
(42,532,265)\end{array}$ & 25.94 \\
\hline 2006 & 33 & $\begin{array}{c}\mathbf{1 8 , 3 0 9 , 2 9 2} \\
(42,111,371)\end{array}$ & $\begin{array}{c}\mathbf{1 4 , 4 2 9 , 6 9 5} \\
(33,188,299)\end{array}$ & 26.89 \\
\hline 2007 & 38 & $\begin{array}{c}\mathbf{1 8 , 0 3 3 , 2 2 4} \\
(41,476,415)\end{array}$ & $\begin{array}{c}\mathbf{1 6 , 2 0 2 , 4 2 0} \\
(37,265,566)\end{array}$ & 11.30 \\
\hline 2008 & 29 & $\begin{array}{c}\mathbf{8 , 6 9 6 , 4 0 6} \\
(20,001,734)\end{array}$ & $\begin{array}{c}\mathbf{8 , 2 1 9 , 4 3 2} \\
(18,904,694)\end{array}$ & 5.80 \\
\hline 2009 & 3 & $\begin{array}{c}\mathbf{1 , 0 9 3 , 3 3 2} \\
(2,514,664)\end{array}$ & $\begin{array}{c}\mathbf{9 1 2 , 3 0 9} \\
(2,098,310)\end{array}$ & 19.84 \\
\hline 2010 & 2 & $\begin{array}{c}\mathbf{1 , 0 3 9 , 3 6 7} \\
(2,390,545)\end{array}$ & $\begin{array}{c}\mathbf{7 4 1 , 8 7 0} \\
(1,706,301)\end{array}$ & 40.10 \\
\hline 2011 & 3 & $\begin{array}{c}\mathbf{3 9 2 , 5 7 8} \\
(902,929)\end{array}$ & $\begin{array}{c}\mathbf{5 6 7 , 3 3 4} \\
(1,304,869)\end{array}$ & -30.80 \\
\hline TOTAL & 232 & $\begin{array}{c}\mathbf{9 2 , 7 2 8 , 9 5 2} \\
(213,276,589)\end{array}$ & $\begin{array}{c}\mathbf{7 2 , 0 3 4 , 5 5 2} \\
(165,679,470)\end{array}$ & 28.73 \\
\hline
\end{tabular}

the distribution is evaluated according to the years, it can be seen that for the construction works belong to year 2011, the total approximate costs obtained through UACM were found to be lower than the total actual costs with a variation of $30.80 \%$ exceptionally. However, it's seen from Table 2 that the variation was reached up to $84.64 \%$ for the year 2003 . From these results, it can be stated that the approximate costs obtained through UACM were delusive. Therefore, for the initial phase of the construction works, in order to estimate the actual costs, a "cost model" was proposed. The statistical features of a set of 64 input data, which were used in the testing stage of cost model, are provided in Table 3.

Within the input parameters of cost model; approximate cost was varied from 143,113 TL to 3,807,421 TL (from $€ 62223$ to $€ 1,655,400$ ), total construction area was varied from $136 \mathrm{~m}^{2}$ to $7500 \mathrm{~m}^{2}$, number of floors was varied from 1 to 5 , building height was varied from $3.20 \mathrm{~m}$ to $16.80 \mathrm{~m}$, and finally contract value was varied from $94500 \mathrm{TL}$ to $2,638,000 \mathrm{TL}$ (from $€ 41087$ to $€ 1,146,957)$. In Table 3 , coefficient of variation values of the approximate cost, total construction area and contract value were higher than the coefficient of variation values of the number of floors and building height. Hence, it can be understood that the data of the approximate cost, total construction area and contract value were less homogeneous than the data of the number of floors and building height. The least homogeneous data were belonging to the parameter of total construction area while the distribution was the most concentrated around arithmetic mean for the building height data.

For the MLP and RBF analyses of the cost model, the optimal values of RMSE, MAE and $\mathrm{R}^{2}$, which were obtained during the test stage of each combination, are given in Table 4.

It's seen from Table 4 that, minimum RMSE value was obtained from MLP method as 65049 TL (€28282) while minimum MAE value was obtained from RBF method as 38475 TL (€16728). Optimal results for MLP method were obtained from the fifth combination that

Table 3. Statistical features of cost model's input parameters at the testing stage

\begin{tabular}{lccccc}
\hline Pefinition & $\begin{array}{c}\text { Approximate } \\
\text { Cost } \\
(\mathrm{TL})\end{array}$ & $\begin{array}{c}\text { Total Constr. } \\
\text { Area } \\
\left(\mathrm{m}^{2}\right)\end{array}$ & $\begin{array}{c}\text { Number } \\
\text { of } \\
\text { Floors }\end{array}$ & $\begin{array}{c}\text { Building } \\
\text { Height } \\
(\mathrm{m})\end{array}$ & $\begin{array}{c}\text { Contract } \\
\text { Value } \\
(\mathrm{TL})\end{array}$ \\
\hline Minimum Value & $143,113.00$ & 136.00 & 1.00 & 3.20 & 94500.00 \\
\hline Maximum Value & $3,807,421.00$ & 7500.00 & 5.00 & 16.80 & $2,638,000.00$ \\
\hline Arithmetic Mean & $1,066,121.75$ & 1866.02 & 2.78 & 9.43 & $749,061.00$ \\
\hline Mean Deviation & $571,332.59$ & 1300.27 & 1.00 & 2.95 & $448,800.59$ \\
\hline Standard Deviation & $776,237.17$ & 1618.24 & 1.19 & 3.69 & $571,181.82$ \\
\hline Coef. of Variation $(\%)$ & 72.81 & 86.72 & 42.72 & 39.17 & 76.25 \\
\hline
\end{tabular}


consists of five inputs, 6 hidden layers, 5 iterations and logsig as activation function. In other words, minimum RMSE value was obtained from neural network architecture form of 5-6-1. Besides, for the all optimal combinations of MLP method (except the third combination), activation function was obtained as logsig. Optimal results for RBF method were also obtained from the fifth combination, which consists of 9 hidden layers and has a value of 1.6 as spreading parameter. In other words, minimum MAE value was obtained from neural network architecture form of 5-9-1. It's clear from Table 4 that, for the fifth combinations of both methods; although RMSE value of MLP method has a small difference from the RMSE value of RBF method, MAE value of RBF method has a significant difference from the MAE value of MLP method. Besides, $R^{2}$ values of the both methods have small differences. As a summary, RBF method is thought to be better than MLP method for the prediction of actual costs.

Comparison of UACM results with MLP and RBF results together with actual costs and estimated costs are presented in Table 5.

As stated previously, total approximate costs obtained through UACM were found to be higher than

Table 4. Optimal results of cost model at the testing stage

\begin{tabular}{lcccc}
\hline \multirow{2}{*}{ Method } & \multirow{2}{*}{$\begin{array}{c}\text { Comb. } \\
\text { Nr. }\end{array}$} & \multicolumn{3}{c}{ Comparison Parameters } \\
\cline { 2 - 5 } & & RMSE & MAE & $R^{2}$ \\
\hline \multirow{4}{*}{ MLP } & 1 & 172890.00 & 110030.00 & 0.9270 \\
\cline { 2 - 5 } & 2 & 161900.00 & 114890.00 & 0.9230 \\
\cline { 2 - 5 } & 3 & 166440.00 & 119880.00 & 0.9300 \\
\hline & 4 & 168360.00 & 143780.00 & 0.9150 \\
\hline \multirow{3}{*}{ RBF } & $\mathbf{5}$ & $\mathbf{6 5 0 4 9 . 0 0}$ & $\mathbf{4 3 4 3 3 . 0 0}$ & $\mathbf{0 . 9 8 8 0}$ \\
\cline { 2 - 5 } & 2 & 172350.00 & 119280.00 & 0.9310 \\
\cline { 2 - 5 } & 3 & 176300.00 & 109670.00 & 0.9240 \\
\hline & 4 & 180850.00 & 118350.00 & 0.9200 \\
\hline & $\mathbf{5}$ & $\mathbf{6 5 9 6 9 . 0 0}$ & $\mathbf{3 8 4 7 5 . 0 0}$ & $\mathbf{0 . 9 8 7 1}$ \\
\hline
\end{tabular}

Table 5. Comparison of UACM-MLP-RBF results (First line: $€$ values, Second line: (TL) values)

\begin{tabular}{lcccc}
\hline Method & $\begin{array}{c}\text { Nr. of } \\
\text { Data }\end{array}$ & $\begin{array}{c}\Sigma(\text { Estimated } \\
\text { Costs }) \\
(a)\end{array}$ & $\begin{array}{c}\Sigma(\text { Actual } \\
\text { Costs }) \\
(b)\end{array}$ & $\begin{array}{c}(a-b) / b \\
(\%)\end{array}$ \\
\hline UACM & 232 & $\begin{array}{c}\mathbf{9 2 , 7 2 8 , 9 5 2} \\
(213,276,589)\end{array}$ & $\begin{array}{c}\mathbf{7 2 , 0 3 4 , 5 5 2} \\
(165,679,470)\end{array}$ & 28.73 \\
\hline MLP & 232 & $\begin{array}{c}\mathbf{7 2 , 8 3 3 , 0 0 1} \\
(167,515,903)\end{array}$ & $\begin{array}{c}\mathbf{7 2 , 0 3 4 , 5 5 2} \\
(165,679,47)\end{array}$ & 1.11 \\
\hline \multirow{2}{*}{ RBF } & 232 & $\begin{array}{c}\mathbf{7 2 , 2 3 4 , 7 3 3} \\
(166,139,885)\end{array}$ & $\begin{array}{c}\mathbf{7 2 , 0 3 4 , 5 5 2} \\
(165,679,470)\end{array}$ & $\mathbf{0 . 2 8}$ \\
\hline
\end{tabular}

the total actual costs with a $28.73 \%$ variance. Besides, estimated costs obtained through MLP were found to be higher than the total actual costs with a $1.11 \%$ variance while the estimated costs obtained through RBF were higher than the total actual costs with a $0.28 \%$ variance. It can be also stated from Table 5 that both ANN methods were showed better performance than the UACM for the estimation of actual construction costs while RBF method was showed a better performance than the MLP method and the most accurate predictions attained from RBF method. Moreover, it can be stated that, some advantageous features of RBF method, which can be listed as; non-iterative structure, usage of non-linear radial basis activation function between the input layer and hidden layer, evaluating the different subspaces of input set as different relationships and producing local solutions, were caused the rich performance of RBF method (Moody, Darken 1989; Chen et al. 1991; Park, Sandberg 1991; Bianchini et al. 1995; Hacıoğlu 2005, 2006; Akbilgiç 2011; Öztemel 2012).

Neural network architecture of optimal RBF analysis, which was obtained from the fifth combination with 9 hidden layers, is illustrated in Figure 3.

For the MLP and RBF analyses, obtaining optimal results from the fifth and the final combinations means that the usage of the approximate cost, total construction area, number of floors, building height and contract value, which are the all input parameters as in Table 3, increased the performance of the cost model and thus the minimum RMSE and MAE values were obtained. However, for the other four combinations of MLP and RBF analyses, both RMSE and MAE values have insignificant differences. It means that the contract value, which is the fifth input parameter of the cost model, has the greatest influence on the cost model. Besides, minimum actual cost value was determined as TL 103,950

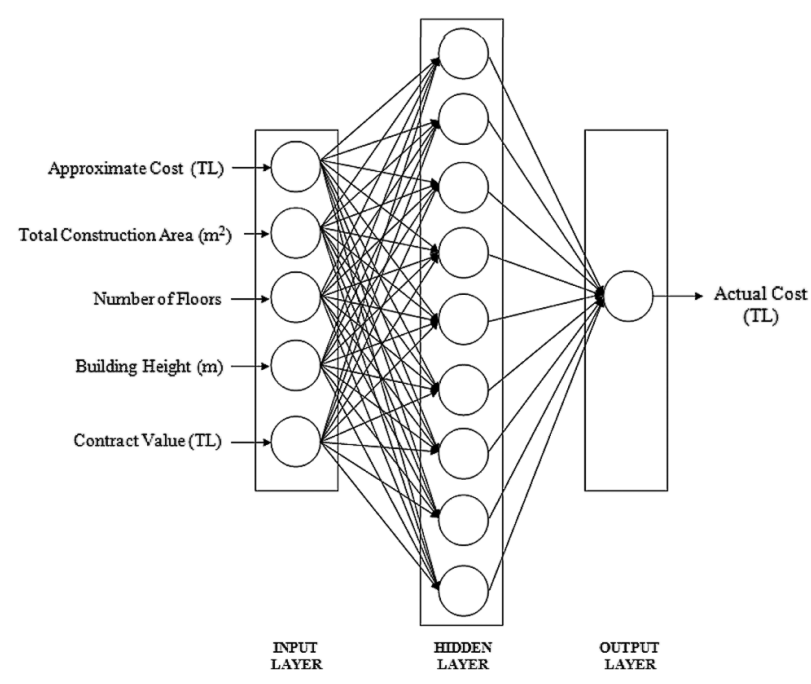

Fig. 3. Neural network architecture of optimal RBF analysis (5-9-1) 
(€45196), median actual cost value was determined as TL 597,300 (€259,696) and maximum actual cost value was determined as TL $2,667,488(€ 1,159,777)$ from the testing stage of the ANN analyses. Minimum, median and maximum values were respectively calculated according to the minimum RMSE, which was obtained from MLP method as TL 65049 (€28282), with the variances of:

variance $_{(\text {Min v. } R M S E)}=\left(\frac{65049}{103,950}\right) x 100=62.58 \%$;

variance $_{(\text {Med vs.RMSE })}=\left(\frac{65049}{597,300}\right) \times 100=10.89 \%$;

$\operatorname{variance}_{(\text {Max vs. } R M S E)}=\left(\frac{65049}{2,667,488}\right) \times 100=2.44 \%$.

First, the minimum RMSE was obtained from MLP method as TL 65049 ( $€ 28282)$, so then, by considering this minimum RMSE, the variance of the actual cost values, which were used during the test stage of the analyses, was calculated. These calculated variances are illustrated in Figure 4.

Minimum, median and maximum actual cost values were respectively calculated according to the minimum MAE, which was obtained from RBF method as TL 38475 (€16728), with the variances of; $37.01 \%$, $6.44 \%$ and $1.44 \%$. Calculated variances of actual cost values, which were used during the test stage of analyses, according to the minimum MAE, which was obtained from RBF method as TL 38475 ( $€ 16728)$, is also respectively illustrated in Figure 5.

Optimal $R^{2}$ values obtained through MLP and RBF methods express that numerical relation between the actual costs and the estimated costs was at $98 \%$ level and the actual costs were estimated by an accurateness of $98 \%$. It is considered that there is a strong correlation between the actual values and the estimated values when $R^{2}>0.80$, (Kayadelen et al. 2009). It was seen that the results of $R^{2}=0.9880>0.80$ and $R^{2}=0.9871>0.80$ for the test stages of MLP and RBF analyses for the proposed

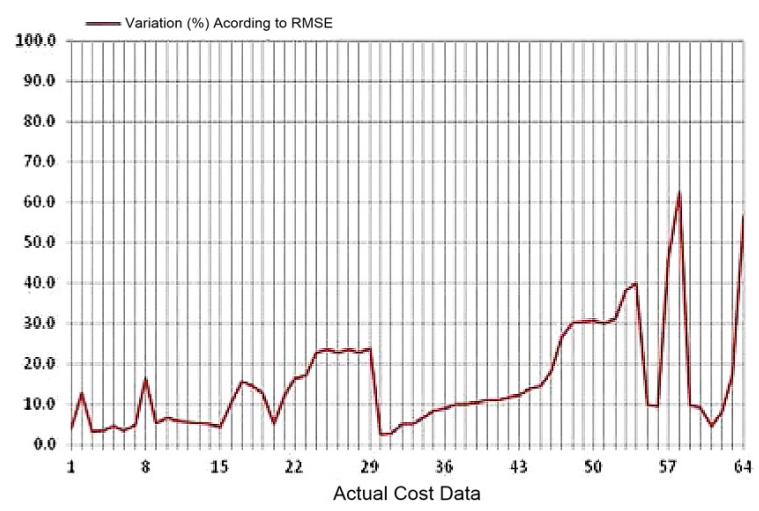

Fig. 4. Variances of actual costs according to minimum RMSE (\%) cost model were at an acceptable level (Kayadelen et al. 2009).

The correlation between the actual costs of 168 public buildings and the estimated costs of the buildings obtained through training stage of RBF method can be seen in Figure 6. Also, the correlation between the actual costs of 64 public buildings and the estimated costs of the buildings obtained through testing stage of RBF method can be seen in Figure 7.

For the both figures, the horizontal axis states the actual cost data while the vertical axis states the estimated cost data obtained through RBF method. Both figures illustrate that the symmetric straight $(y=x)$ and trend line were very close to each other. It can be referred from the figures that the data were concentrated in the vicinity of the trend line. Therefore, it can obviously be stated that the actual cost data and the estimated cost data were very close to each other and RBF analysis was successful. The correlation between actual cost data and estimated cost data, which was obtained from RBF method, validates the claim. $\mathrm{R}^{2}$ was calculated as 0.9941 for the training stage while it was calculated from testing stage as 0.9871 . It's known that if $R^{2}>0.80$ there's a strong correlation between actual values and model estimations (Kayadelen et al. 2009). Thus, the results of $R^{2}=0.9941>0.80$ and

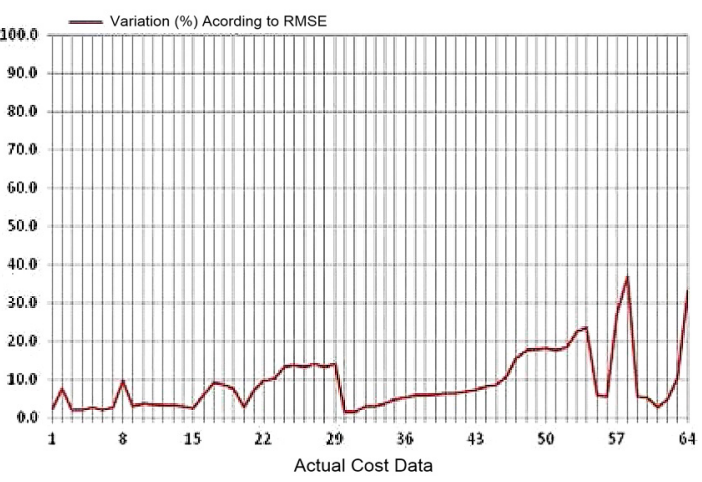

Fig. 5. Variances of actual costs according to minimum MAE (\%)

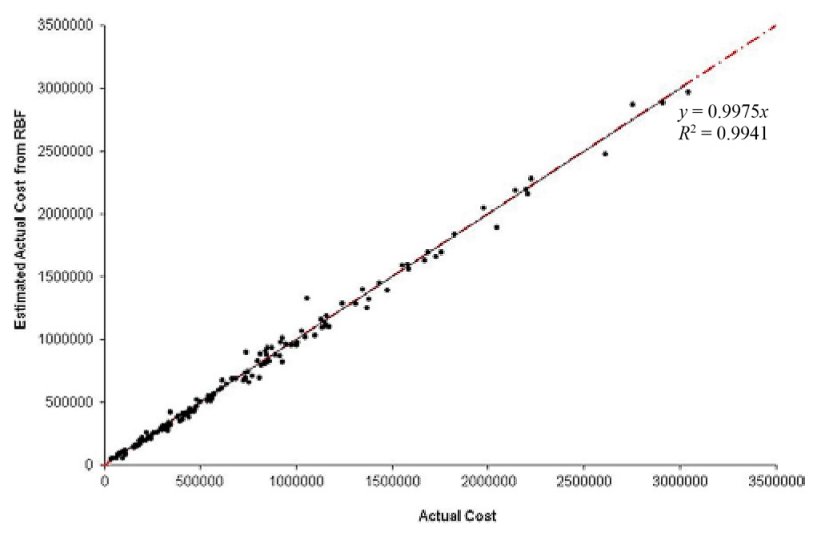

Fig. 6. Correlation between actual costs and optimal RBF results at the training stage 


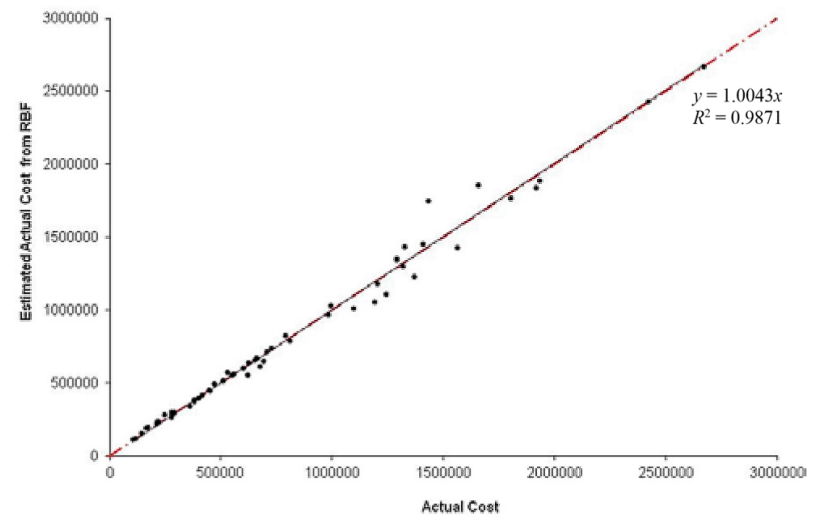

Fig. 7. Correlation between actual costs and optimal RBF results at the testing stage

$R^{2}=0.9871>0.80$ are at acceptable level (Kayadelen et al. 2009).

\section{Conclusions}

In this current study, the tender files of the 232 building projects in total were reviewed. All these projects were completed between 2003 and 2011 in Bursa, Ankara and Gaziantep, which are the metropolitans of Turkey's different geographic regions. In application, principally unit area cost method (UACM), which is commonly used in Turkey, was dealt with and the approximate cost of each construction work was calculated in accordance with this method. By comparing the approximate costs (calculated through UACM) and the actual costs (obtained through archive studies), it was aimed to determine the accuracy of the UACM. It was stated that, the total approximate costs calculated through UACM were found to be higher than the total actual costs with a $28.73 \%$ variance. Besides, the result of $R^{2}=0.6954<0.80$ was at unacceptable level. Hence, it was proved that the actual costs and approximate costs of UACM have significant differences. Therefore, for the initial phase of the construction works, in order to estimate the actual costs realistically, a "cost model", which was comprised five combinations, was proposed. The input parameters of the cost model are approximate cost, total construction area, number of floors, building height and contract value, while the only one output parameter is actual cost. Analyses were repeated with MLP and RBF methods, which are typically used in ANN applications, for the five combinations of the cost model. Root mean square error (RMSE), mean absolute error (MAE) and coefficient of determination $\left(R^{2}\right)$ were calculated for the comparison of actual costs and estimated costs. Besides, variances between the actual costs and the estimated costs were calculated. Thus, the performances of UACM approach and ANN methods were evaluated comparatively.

For the cost model, minimum RMSE was obtained from MLP method as TL 65049 (€28282) while minimum MAE was obtained from RBF method as TL 38475 (€16728). It was considered that these mon- etary error measures were satisfactory when the average actual cost, TL 714,135.65 (€310,494), was taken into account. The minimum, median and maximum actual costs were, respectively, calculated according to the minimum RMSE with the variances of; $62.58 \%, 10.89 \%$ and $2.44 \%$, while according to the minimum MAE with the variances of; $37.01 \%, 6.44 \%$ and $1.44 \%$. The variances of median and maximum actual costs were found to be at an acceptable range. Besides, at the testing stage of MLP analysis, $R^{2}$ was obtained as 0.9880 while it was obtained at the testing stage of RBF analysis as 0.9871 . Both $R^{2}$ values were over 0.80 and the correlation between the actual values and the estimated values were too strong.

Finally, estimated costs through MLP were found to be higher than the total actual costs with a $1.11 \%$ variance while the estimated costs through RBF were higher than the total actual costs with a $0.28 \%$ variance and total approximate costs through UACM were higher than the total actual costs with a $28.73 \%$ variance.

As a result, for the initial phase of the construction works, it was found that the MLP and RBF methods were better than UACM approach in their ability to estimate the actual costs. When the both ANN methods were evaluated between each other, it was determined that RBF method was superior to MLP method and optimal RBF performance was obtained from the fifth combination with the neural network architecture form of 5-9-1. It was stated that, some advantageous features of RBF method like; non-iterative structure, usage of non-linear radial basis activation function between the input layer and hidden layer, evaluating the different subspaces of input set as different relationships and producing local solutions, had been caused the rich performance of RBF method. Although the most satisfactory results were obtained through RBF method, it should be considered that the performance of MLP method was at acceptable level, too. In conclusion, it was found out that existing UACM approach may cause misleading estimations of public construction costs and the usage of proposed cost model with RBF and MLP methods for construction cost estimates is better than UACM in its ability to estimate construction costs. By increasing the number of data and the combinations of the cost model, analyses may be repeated with addition of other cost estimation methods in the future studies.

\section{Acknowledgement}

The authors would like to thank Scientific Research Projects (SRP) Coordination Unit of Erciyes University, Turkey for the contribution to PhD thesis (FBD-11-3566).

\section{References}

Adeli, H.; Wu, M. 1998. Regularization neural network for construction cost estimation, Journal of Construction Engineering and Management 124(1): 18-24.

http://dx.doi.org/10.1061/(ASCE)0733-9364(1998)124:1(18) 
Akbilgiç, O. 2011. Hibrit radyal tabanlı fonksiyon ă̆ları ile değişken seçimi ve tahminleme: menkul kıymet yatırım kararlarına ilişkin bir uygulama [Variable selection and estimation with hybrid radial basis function networks: an application for security investment decisions]: $\mathrm{PhD}$ Thesis. Istanbul University, Istanbul, Turkey.

Akınbingöl, M.; Gültekin, A. T. 2005. Bina üretimi yapım evresinde maliyet planlama ve denetimine yönelik bir maliyet yönetim modeli önerisi [Proposal for a cost management model on cost planning and its control in the building construction phase], Journal of the Faculty of Engineering and Architecture of Gazi University 20(4): 499-505.

Arafa, M.; Alqedra, M. 2011. Early stage cost estimation of buildings construction projects using artificial neural networks, Journal of Artificial Intelligence 4(1): 63-75. http://dx.doi.org/10.3923/jai.2011.63.75

Arslan, O.; Kurt, O.; Konak, H. 2007. Yapay sinir ağlarının jeodezide uygulamaları üzerine öneriler [Suggestions on geodesy applications of artificial neural networks], in 11 . Türkiye Harita Bilimsel ve Teknik Kurultayı, 2-6 April 2007, Ankara, Turkey.

Ashworth, A. 2010. Cost studies of buildings. $5^{\text {th }}$ ed. Pearson Education, Great Britain. 562 p.

Baalousha, Y.; Çelik, T. 2011. An integrated web-based data warehouse and artificial neural networks system for unit price analysis with inflation adjustment, Journal of Civil Engineering and Management 17(2): 157-167. http://dx.doi.org/10.3846/13923730.2011.576806

Bari, N. A. A.; Kadir, M. R. A.; Ismail, N.; Yusuff, R. M. 2008. Exploring the types of construction cost modelling for industrialised building system (IBS) projects in Malaysia, in The $1^{\text {st }}$ International Conference on Industrialised, Integrated, Intelligent Construction (I3CON), 14-16 May 2008, Loughborough, UK.

Bayram, S.; Öcal, M. E.; Laptalı Oral, E. 2012. Analysis of cost and schedule variances in construction works with artificial intelligence approaches: the case of Turkey, in International Students' Conference of Civil Engineering (ISCCE 2012), 10-11 May 2012, Tirana, Albania.

Bhokha, S.; Ogunlana, S. O. 1999. Application of artificial neural network to forecast construction duration of buildings at the predesign stage, Engineering, Construction and Architectural Management 6(2): 133-144. http://dx.doi.org/10.1108/eb021106

Bianchini, M.; Frasconi, P.; Gori, M. 1995. Learning without local minima in radial basis function networks, IEEE Transactions on Neural Networks 6(3): 749-755. http://dx.doi.org/10.1109/72.377979

Broomhead, D. S.; Lowe, D. 1988. Multivariable functional interpolation and adaptive networks, Complex Systems 2: 321-355.

Chen, S.; Cowan, C. F. N.; Grant, P. M. 1991. Orthogonal least squares learning algorithm for radial basis function networks, IEEE Transactions on Neural Networks 2(2): 302-309. http://dx.doi.org/10.1109/72.80341

Civelekoğlu, G. 2006. Arıtma proseslerinin yapay zekâ ve çoklu istatistiksel yöntemler ile modellenmesi [The modeling of treatment processes with artificial intelligence and multistatistical methods]: PhD Thesis. Süleyman Demirel University, Isparta, Turkey.

Emsley, W. E.; Lowe, D. J.; Duff, A. R.; Harding, A.; Hickson, A. 2002. Data modelling and the application of a neural network approach to the prediction of total construction costs, Construction Management and Economics 20(6): 465-472. http://dx.doi.org/10.1080/01446190210151050

Eren, B.; Eyüpoğlu, V. 2011. Yapay sinir ağları ile Ni(II) iyonu geri kazanım veriminin modellenmesi [Modelling of recovery efficiency of $\mathrm{Ni}(\mathrm{II})$ ion using artificial neural network], in 6th International Advanced Technologies Symposium (IATS'11), 16-18 May 2011, Elazı̆̆, Turkey.

Fine, T. L. 1999. Feedforward neural network methodology. Springer-Verlag, USA. 352 p.

Göktürk, İ. 2007. Inş̧aat sektöründe fizibilite aşamasında maliyet tahmini yapmakta karşılaşılan zorluklar ve çözüm önerileri üzerine bir değerlendirme [An evaluation about difficulties and solutions in the step of cost estimating for feasibility process in the construction sector]: MSc Thesis. İstanbul Teknik Üniversitesi, İstanbul, Turkey.

Günaydın, H. M.; Doğan, S. Z. 2004. A neural network approach for early cost estimation of structural systems of buildings, International Journal of Project Management 22(7): 595-602.

http://dx.doi.org/10.1016/j.ijproman.2004.04.002

Hacıoğlu, A. 2005. A novel usage of neural network in optimization and implementation to the internal flow systems, Aircraft Engineering and Aerospace Technology 77(5): 369-376. http://dx.doi.org/10.1108/00022660510617095

Hacıoğlu, A. 2006. Hızlı evrimsel eniyileme için yapay sinir ağ1 kullanılması [Using artificial neural network for rapid evolutionary optimization], Journal of Aerospace Technology 2(3): 1-8.

Helvac1, A. 2008. Comparison of parametric models for conceptual duration estimation of building projects: MSc Thesis. Middle East Technical University, Ankara, Turkey.

Jain, A. K.; Mao, J. C.; Mohiuddin, K. M. 1996. Artificial neural networks: a tutorial, Computer 29(3): 31-44. http://dx.doi.org/10.1109/2.485891

Kangilaski, T. 2002. Feed-forward neural networks for smooth operation of the high-voltage power transmission network, Proceedings of the Estonian Academy of Sciences Engineering 8(4): 223-247.

Kaveh, N. S.; Ashrafizadeh, S. N.; Mohammadi, F. 2008. Development of an artificial neural network model for prediction of cell voltage and current efficiency in a chlor-alkali membrane cell, Chemical Engineering Research and Design 86(5): 461-472. http://dx.doi.org/10.1016/j.cherd.2007.12.009

Kayadelen, C.; Taşkıran, T.; Günaydın, O.; Fener, M. 2009. Adaptive neuro-fuzzy modeling for the swelling potential of compacted soils, Environmental Earth Sciences 59(1): $109-115$. http://dx.doi.org/10.1007/s12665-009-0009-5

Kaynar, O.; Taştan, S.; Demirkoparan, F. 2010. Ham petrol fiyatlarının yapay sinir ağları ile tahmini [Crude oil price forecasting with artificial neural networks], Ege Academic Review 10(2): 559-573.

Kim, G. H.; An, S. H.; Kang, K. I. 2004. Comparison of construction cost estimating models based on regression analysis, neural networks and case-based reasoning, Building and Environment 39(10): 235-1242. http://dx.doi.org/10.1016/j.buildenv.2004.02.013

Kim, G. H.; Seo, D. S.; Kang, K. I. 2005. Hybrid models of neural networks and genetic algorithms for predicting preliminary cost estimates, Journal of Computing in Civil Engineering 19(2): 208-211.

http://dx.doi.org/10.1061/(ASCE)0887-3801(2005)19:2(208)

Kolaylığlu, Ö. 2006. Inșaat sektöründe proje yönetimi ve proje yöneticisi [Project management and project manager in construction sector]: MSc Thesis. Dokuz Eylül University, Izmir, Turkey.

Kumanlığlu, A. A.; F1stıkoğlu, O. 2011. Kavramsal bir hidrolojik modele yapay zeka entegrasyonu ve model performanslarinin Gediz nehri havzasinda irdelenmesi [Integration of artificial intelligence to a conceptual hydrologic model and semtinizing of model performances on Gediz 
river basin], Tehnical Bulletin, Water Resources Agency of Turkey 111: 25-43.

Kuşan, H.; Aytekin, O.; Özdemir, İ. 2009. Comparison of fuzzy logic, artificial neural network and multiple regression analysis methods in the determination of selling prices of residences, in Fifth International Conference on Construction in the $21^{\text {st }}$ Century (CITC-V), 20-22 May 2009, Istanbul, Turkey.

Liu, X. 1998. An artificial neural network approach to assess project cost and time risks at the front end of projects: MSc Thesis. The University of Calgary, Canada.

MATLAB, Version 7.9.0. The MathWorks Inc., Massachusetts, USA [online], [cited 12 August 2009]. Available from Internet: http:/www.mathworks.com

Moody, J.; Darken, C. J. 1989. Fast learning in networks of locally-tunes processing units, Neural Computation 1(2): 281-294. http://dx.doi.org/10.1162/neco.1989.1.2.281

Oral, M.; Laptalı Oral, E.; Aydın, A. 2012. Supervised vs. unsupervised learning for construction crew productivity prediction, Automation in Construction 22: 271-276. http://dx.doi.org/10.1016/j.autcon.2011.09.002

Öztemel, E. 2012. Yapay Sinir A ğları [Artificial Neural Networks]. Papatya Publishing, Turkey. 232 p.

Park, J.; Sandberg, I. W. 1991. Universal approximations using radial-basis-function network, Neural Computation 3(2): 246-257. http://dx.doi.org/10.1162/neco.1991.3.2.246

Powell, M. J. D. 1987. Radial basis functions for multivariable interpolation: a review, in Algorithms for approximation. New York: Clarendon Press, 143-167.
Singh, K. P.; Basant, A.; Malik, A.; Jain, G. 2009. Artificial neural network modeling of the river water quality: a case study, Ecological Modelling 220(6): 888-895. http://dx.doi.org/10.1016/j.ecolmodel.2009.01.004

Siqueira, I. 1999. Neural network-based cost estimating: MSc Thesis. Concordia University, Montreal, Canada.

Sönmez, R. 2004. Conceptual cost estimation of building projects with regression analysis and neural networks, Canadian Journal of Civil Engineering 31: 677-683. http://dx.doi.org/10.1139/104-029

Uğur, L. O. 2007a. Yapı maliyetinin yapay sinir ăgl ile analizi [Analysis of construction costs with artificial neural networks]: PhD Thesis. Gazi University, Ankara, Turkey.

Uğur, L. O. 2007b. İnşaat firmalarının maliyet ve süre belirleme yöntemleri üzerine bir alan çalışması [A field study on the methods for cost and duration determination of construction firms], in 4. Inşaat Yönetimi Kongresi, 30-31 October 2007, İstanbul, Turkey.

Uğur, L. O. 2009. Yapı maliyeti çalışmaları [Construction cost studies]. $1^{\text {st }}$ ed. Alter Publishing, Turkey. $567 \mathrm{p}$.

Uncuoğlu, E. 2003. Kaba daneli zeminlerde sükûnetteki toprak basıncı katsayısının yapay sinir ağları ile bulunması [The estimation of the coeffiecient of earth pressure at rest in cohesionless soils by artificial neural networks]: MSc Thesis. Erciyes University, Kayseri, Turkey.

Werbos, P. J. 1994. The Roots of Back Propagation: From ordered derivatives to neural networks and political forecasting. New York: John Wiley \& Sons. 320 p.

Savas BAYRAM. PhD, Assistant Professor of Civil Engineering Department in the Faculty of Engineering at Erciyes University, Turkey. He is actively involved in construction cost management. He received his PhD degree in Civil Engineering at the Erciyes University in 2013.

M. Emin OCAL. PhD, Professor of Civil Engineering Department in the Faculty of Engineering and Architecture at Cukurova University, Turkey. He is actively involved in construction management.

Emel LAPTALI ORAL. PhD, Professor of Civil Engineering Department in the Faculty of Engineering and Architecture at Cukurova University, Turkey. She is actively involved in construction management.

C. Duran ATIS. PhD, Professor of Civil Engineering Department in the Faculty of Engineering at Erciyes University, Turkey. He is actively involved in construction materials and construction management. 